\title{
A case of Seronegative Acetylcholine-Receptor Autonomic Autoimmune Neuropathy
}

\section{Souheil Edmond Gebeily*, Ahmad Houjeiri and Samer El Rayess}

Department of Neurology, Neuroscience Research Center - The Lebanese University

${ }^{*}$ Corresponding author: Gebeily SE, Department of Neurology, Neuroscience Research Center - The Lebanese University Hospital, Lebanon, Tel: +9611897767; E-mail: souheil.gebeily@gmail.com

Received date: November 02, 2015; Accepted date: December 22, 2015; Published date: January 02, 2016

Copyright: @ 2015 Gebeily, et al. This is an open-access article distributed under the terms of the Creative Commons Attribution License, which permits unrestricted use, distribution, and reproduction in any medium, provided the original author and source are credited.

\section{Abstract}

Autonomic neuropathies may occur primarily or secondarily to various underlying diseases. Autoimmune autonomic neuropathy also called autoimmune autonomic ganglionopathy is a rare acquired autoimmune neuropathy characterized by pandysautonomia, usually associated to autoantibodies to ganglionic nicotinic acetylcholine receptors found in more than $50 \%$ of cases. Neurogenic orthostatic hypotension is a major symptom of dysautonomia and may cause serious impairment in patients' quality of life. We present a case of autonomic autoimmune neuropathy in a seronegative patient for acetylcholine receptors antibodies with good recovery after treatment with IVIg, raising the issue of some forms of pure autonomic failure which can have identical phenotype, respond similarly to immunotherapy, but may be related to antibodies directed at different targets in nerve or ganglion.

Keywords: Neurogenic orthostatic hypotension; Autonomic autoimmune neuropathy

\section{Background}

Autoimmune autonomic ganglionopathy (AAG) is a rare acquired pan-dysautonomia, in which autoantibodies to ganglionic nicotinic acetylcholine receptors (gAChR) may play a central role. Young et al. originally described AAG in 1975 as "Pure Pan-Dysautonomia with recovery" and by [1] as a "cholinergic dysautonomia". This syndrome was associated with autoantibodies to ganglionic nicotinic acetylcholine receptors (G-AChR) in 1998 [2] .

Primary syndromes of generalized autonomic failure include the following groups: Idiopathic orthostatic hypotension and other forms of pure autonomic failure (PAF). Autoimmune autonomic neuropathy (AAN), Multiple system atrophy (MSA). AAG and AAN are actually usually adopted to describe this subacute or chronic condition linked to antibodies to G-AChR. Clinical presentation is usually a monophasic progression occurring in a previous healthy patient evolving to peek intensity of autonomic dysfunction within few days or weeks in the acute or subacute onset cases.

The spectrum and severity of dysautonomia varies from patient to patient. The most common pattern, occurring in about two thirds of patients, is severe generalized sympathetic and parasympathetic autonomic failure, whereas, somatic nerve fibers are totally or relatively spared. A viral infection episode is more often than not reported previous to the illness onset, suggesting the autoimmune origin [3]. The aim of this case report is to underline that the diagnosis of autonomic autoimmune neuropathy with pure autonomic failure can still be strongly considered in the absence of acetylcholine receptors antibodies and good recovery after treatment with IVIg. This would raise the need for further research in identifying new classes of antibodies that would be directed at different targets in nerve or ganglion.

\section{Definitions}

According to "The Consensus Committee of the American Autonomic Society and the American Academy of Neurology" [4-5]:

Orthostatic hypotension "is defined as a sustained fall of systolic blood pressure by at least $20 \mathrm{mmHg}$ or diastolic blood pressure by $10 \mathrm{mmHg}$ within 3 minutes of standing or head-up tilt"[6].

Neurogenic orthostatic hypotension (NOH): a sign of cardiovascular autonomic dysfunction caused by a failure of noradrenergic neurotransmission that that can arise from primary degenerative disorders known as $\alpha$-synucleopathies such as PAF, Parkinson's disease (PD) with autonomic failure, dementia of lewy body (DLB), MSA; secondary causes of NOH are related to systemic conditions that induce peripheral nerve functions such as diabetic and non-diabetic neuropathies.

Pure autonomic failure (PAF): a pathologic condition characterized by severe $\mathrm{NOH}$ associated with insidious onset, slow progression, modest gastrointestinal impairment, marked supine hypertension and often very low plasma noradrenalin plasma levels. Idiopathic orthostatic hypotension, sometimes also referred to as Bradbury-Eggleston syndrome is often included in this category. 
Postural orthostatic tachycardia syndrome (POTS): characterized by the increase in heart rate on standing, without significant decrease in blood pressure and is a relatively benign disorder that is often self-limiting [7].

\section{Case report}

In June 2005, this 54 year-old lady was admitted to our neurological unit as she presented for the past few weeks recurrent falls, dizziness, walking impairment, recurrent syncope while standing, feeling of unexplained cold and burning sensation in both feet; more recently she complained from abdominal pain, right-sided cervical and temporomandibular intense neuropathic-like painful sensation, including burning sensation, shooting and paresthesias with intermittent facial and cervical flashing episodes; these symptoms were rapidly increasing to the extent that this patient refrained from standing up from her bed by fear of falling and fainting.

From her past medical history, she had in 1990 an openheart surgery for tricuspid valve stenosis with uneventful postsurgery follow up since then. For the past few weeks, she reports fatigue and diffuse myalgia; she also reported that she had two months earlier an episode of flu-like syndrome with fever of undetermined etiology that resolved spontaneously. No familial history was reported.

From her clinical examination, when lying in bed, her blood pressure (BP) was 105/65 $\mathrm{mmHg}$ and pulse rate was regular at $85 / \mathrm{min}$ falling immediately to systolic BP of $55 \mathrm{mmHg}$ but her heart rate was unchanged at $86 / \mathrm{min}$; tendon reflexes were present in both upper limbs but absent in both lower limbs with no motor or sensory deficit, except for a decreased vibration sense of both feet and slow pupil reactivity to light, more obvious on the right eye; pulse rate remained unchanged for carotid massage, oculocardiac reflex performed under EKG monitoring .

A Tilt test was performed showing a severe orthostatic hypotension with pulse dissociation and absence of the Vasalva maneuver. Abdominal ultrasound was unremarkable except for an asymptomatic $2 \mathrm{~cm}$ gall bladder calculus.

Nerve conduction study was performed on the four limbs showing normal motor and sensory potentials in term of amplitude and velocities, however, $\mathrm{F}$ and $\mathrm{H}$ waves were absent in both tibial and peroneal nerves. Repetitive stimulation showed no abnormality with regard of any incremental or decremental responses to low and high frequencies of stimulation.

The brain MRI was unremarkable. A lumbar tab was performed with normal findings from the cerebral spinal fluid (CSF): albumin $45 \mathrm{mg} / \mathrm{dL}$, white blood cells were absent, IgG: $2.57 \mathrm{mg} / \mathrm{dL}$, glucose $0.66 \mathrm{mg} / \mathrm{dL}$ (for a serum glucose of 98 $\mathrm{mg} / \mathrm{dL}$ ). Routine and immunological tests were negative in the serum: sedimentation rate: $19 \mathrm{~mm}$ (first hour), negative Creactive protein (C-RP), creatinine: $0.64 \mathrm{mg} / \mathrm{dL}$, antibodies against cell nuclei (ANA) was slightly elevated $(1 / 160)$ in the serum and absent in the CSF, the ANA screening profile showed an increased of anti-SSb antibodies (but not anti-SSa) at $138 \mathrm{U} / \mathrm{mL}$ (normal range 0-73 U/mL); antineutrophil cytoplasmic antibodies (ANCA - C, ANCA-P) and anti-DNA antibodies were negative and the rheumatoid factor was slightly but not significantly elevated $(17.9 \mathrm{U} / \mathrm{mL})$; human immunodeficiency virus (HIV), Treponema pallidum haemagglutination (TPHA) immunoassay tests and tuberculine intradermoreaction were negative; cortisol levels were normal in the 24 hours urine and in the serum analysis, thyroid and ACTH hormones levels were within normal range in the serum. Testing for the Anti-ganglioside antibodies profile (GM1, GD1a, GD1b, GM2, GQ1b), anti-Glutamic decarboxylase antibodies ( anti-GAD) and anti-acetylcholine receptors antibodies (Ach-R) were negative.

IgG antibodies were slightly elevated in the serum for antiherpes simplex type 1 (HSV1) at $28 \mathrm{AU} / \mathrm{mL}$ (normal range: 0 11) but IgM antibodies were absent; anti-herpes simplex type 2 (HSV2) IgG and IgM were negative; anti-cytomegalovirus (CMV) IgG were positive at $241 \mathrm{AU} / \mathrm{mL}$ ( normal range: $0-15$ ) but IgM were negative; IgG antibodies anti-Herpes Zoster were elevated at $40 \mathrm{AU} / \mathrm{mL}$ (normal range: 0-12), but IgM were negative.

The diagnostic of post-infectious autoimmune autonomic ganglionopathy (AAG) was considered; Solumedrol $500 \mathrm{mg}$ IV daily infusion was given for five consecutive days but failed in improving significantly the clinical symptoms except for some relief on pain. IV Ig (Sandimmune ${ }^{\circledR}$ ) $400 \mathrm{mg} / \mathrm{Kg}$ over three days rapidly improved significantly, the autonomic failure symptoms by reducing the orthostatic hypotension to the extent that she could stand up supported by compressing stockings; another cure was given two weeks later which dramatically improved the patient's status as the patient recovered of most of her daily activities, with the support of a daily fludrocortisone 0.1 mg oral therapy. Since then was almost asymptomatic with occasionally some light headedness on standing position with mild and well tolerated orthostatic hypotension, though, she could walk long distances with no assistance and follow up was uneventful; however, fludrocortisone was resumed intermittently as orthostatic hypotension fluctuated.

\section{Discussion}

Classified primary autonomic failure into three categories: Parkinson's disease with autonomic failure, multiple system atrophy (MSA), and pure autonomic failure(PAF) [8].

In 1996, a consensus statement was established concerning PAF, MSA and orthostatic hypotension: Pure autonomic failure (PAF) syndromes, including idiopathic orthostatic hypotension, Bradbury-Eggleston syndrome are considered degenerative postganglionic autonomic disorders [9]. Reports on the spectrum of autoimmune autonomic neuropathies that some patients may have a clinical course that resembled a degenerative condition, like PAF, with slow onset and continuous progression [10].

Autonomic neuropathies share common clinical features, among which the most common triad of presenting symptoms is orthostatic hypotension, anhidrosis and gastrointestinal 
dysfunction. Other symptoms may also coexist such as dry eyes and mouth, temperature deregulation, skin trophic changes, reduced or accentuated sweating, erectile or ejaculatory failure, and micturition dysfunction. Young in his original paper considered this pathology as an autonomic variant of Guillain-Barre' syndrome I. An immune- mediated process may explain our patient presentation in contrast with what usually is described in cases with a degenerative mechanism: the acute onset, the monophasic course, selectivity of autonomic fiber involvement with minimal sensory symptoms and most importantly, the dramatic improvement after immunotherapy with immunoglobulins I VIg; moreover, the possible role of the previous infectious viral episode, most probably related to $\mathrm{CMV}$ infection or reactivation as suggested by the high serum IgG levels that also increased few weeks later. The increased serum level of anti-La/SSa antibodies and the presumed sicca complex would raise the association with Sjögren's disease as reported in the literature; however, salivary glands biopsy was note performed to confirm this possibility [11]. Serum AChR antibodies are usually present in high levels (>0.5 nmol/L) in more than $50 \%$ of AAN cases; moreover, ganglionic subunit nicotinic AChR antibodies are more specific to the positive diagnosis and are usually increased in the serum. G-AChR antibodies recognize the alpha3 subunit ,thus they do not bind to other nicotinic receptors. Several studies have reported that these G-AChR autoantibodies induce the internalization of cell-surface nicotinic G-AChRs and thereby impair synaptic transmission [12-14]. There is a lesser chance to identify these specific antibodies in case of slowly progressive forms as highlighted by [14]. In our case, the AChR antibodies were found absent and G-AChR serum antibodies test was not available, however, negative results would not exclude the diagnosis of AAN. Presumably, the antibody negative cases of AAN, which can have identical phenotype and respond similarly to immunotherapy, may be related to antibodies directed at different targets in nerve, including ganglion [15]. Autonomic failure with disabling orthostatic hypotension is the clinical hallmark of PAF which would be considered more as a syndrome with multiple underlying etiologies than a single disease; this may apply also for Postural orthostatic tachycardia syndrome (POTS) characterized by the increase in heart rate on standing, without significant decrease in blood pressure and is a relatively benign disorder that is often selflimiting; however, this syndrome may be associated with other neuropathic variants [16] Kaufmann raises the eventual correlation with an underlying synucleinopathy, with Lewy bodies affecting primarily the autonomic ganglia neurons [17].

The time course and pattern of progression would have slower functional deterioration and a better prognosis in PAF syndromes than in MSA [18]. Some limitations are to be underlined: 1) there is limited available published data considering the rarity of AAG that is most probably underdiagnosed. 2) The spectrum of autoimmune neuropathies has overlapping entities - particularly with other degenerative diseases - as previously highlighted. 3) Specific ganglionic subunit nicotinic AChR antibodies laboratory testing is still of limited availability in clinical practice. 4) They may be other autoimmune mechanisms that are still to be identified among other specific antibodies against nerve and ganglion.

\section{Conclusion}

$\mathrm{NOH}$ are associated to a variety of primary degenerative neurological conditions and may be secondary to diseases involving peripheral neuropathies, some of them of autoimmune aetiology such as AAG involving antibodies against ganglionic nicotinic acetylcholine receptors. This report illustrates well a classic case of acute or sub-acute autonomic autoimmune neuropathy (AAN) with disabling orthostatic hypotension that almost totally and sustainably recovered after IVIg treatment, though AchR antibodies were negative, raising the fact that negative $A C h R$ autoantibodies would not exclude the diagnosis of AAN among other forms of pure autonomic failure (PAF) which can have identical phenotype, respond similarly to immunotherapy, but may be related to antibodies directed at different targets in nerve or ganglion . This would be an opportunity for further research studies.

\section{References}

1. Young RR, Asbury AK, Corbett JL, Adams RD (1975) Pure pan dysautonomia with recovery. Description and discussion of diagnostic criteria. Brain 98: 613-636.

2. Vernino S, Adamski J, Kryzer TJ, Fealey RD, Lennon VA (1998) Neuronal nicotinic ACh receptor antibody in subacute autonomic neuropathy and cancer-related syndromes. Neurology 50: 1806-1813.

3. Suarez GA, Fealey RD, Camilleri M, Low PA (1994) Idiopathic autonomic nephropathy: clinical, neurophysiologic and follow up studies on 27 patients. Neurology 44:1675-1682.

4. Kaufman H (1996) The Consensus Committee of the American Autonomic Society and the American Academy of Neurology. Neurology 46: 1470

5. Metzler M, Duerr S, Granata R, Krismer F, Robertson D, et al. (2012) Neurogenic orthostatic hypotension: pathophysiology, evaluation, and management. J Neurol 260: 2212-2219.

6. Freeman R, Wieling W, Axelrod FB, Benditt DG, Benarroch E, et al. (2011) Consensus statement on the definition of orthostatic hypotension, neutrally mediated syncope and the postural tachycardia syndrome. Clin Auton Res 21: 69-72.

7. Grubb BP, Kosinski DJ, Boehm K, Kip K (1997) The postural orthostatic tachycardia syndrome: a neurocardiogenic variant identified during head-up tilt table testing. Pacing Clin Electrophysiol 20: 2205-2212.

8. Bannister R, Mathias C, Polinsky R (1988) Autonomic failure. In: A textbook of clinical disorders of the autonomic nervous system(2ndedn). Oxford: Oxford University Press, pp. 267-288.

9. Kaufman H (1996) The Consensus Committee of the American Autonomic Society and the American Academy of Neurology. Neurology 46: 1470.

10. Klein CM, Vernino S, Lennon VA, Sandroni P, Fealey RD, et al. (2003) The spectrum of autoimmune autonomic neuropathies. Ann Neurol 53: 752-758.

11. Mori K, lijima M, Koike H, Hattori N, Tanaka F, et al. (2005) Brain. E pub 2518-2534. 
12. Nakane S, Higuchi O, Koga M, Kanda T, Murata K, et al. (2015) Clinical Features of Autoimmune Autonomic Ganglionopathy and the Detection of Subunit-Specific Autoantibodies to the Ganglionic Acetylcholine Receptor in Japanese Patients. PLoS One 10.

13. Shota Kobayashi, Shigeru Yokoyama, Takahiro Maruta, Akiko Muroyama, Hiroaki Yoshikawa et al. (2013) Attenuation of nicotine-evoked $\mathrm{Ca} 2+$ influx by antibody to the nicotinic acetylcholine receptor $\alpha 3$ subunits in human embryonic kidney cells. J Neuroimmunol 257: 102-106.

14. Wang Z, Low PA, Jordan J, Freeman R, Gibbons CH, et al. (2007) Autoimmune autonomic ganglionopathy: IgG effects on ganglionic acetylcholine receptor current. Neurology 68:1917-1921.
15. Sandroni P, Low PA (2009) Other autonomic neuropathies associated with ganglionic antibody. Auton Neurosci. Auton Neurosci 146: 13-17.

16. Thieben MJ, Sandroni P, Sletten DM, Benrud-Larson LM, Fealey $\mathrm{RD}$, et al. (2007) Postural orthostatic tachycardia syndrome: the Mayo clinic experience. Mayo Clin Proc 82: 308-313.

17. Kaufmann H, Biaggioni I (2003) Autonomic failure in neurodegenerative disorders. Semin Neurol 23: 351-363.

18. Mabuchi $N$, Hirayama $M$, Koike $Y$, Watanabe $H$, Ito $H$, et al. (2005) Progression and prognosis in pure autonomic failure (PAF): comparison with multiple system atrophy. J Neurol Neurosurg Psychiatry 76: 947-952. 